\title{
Shleleifhe Sandeskunde
} $-\infty$

$3 \mathfrak{u m} 25 \mathfrak{j a ̈ h \mathfrak { h i g e n }}$

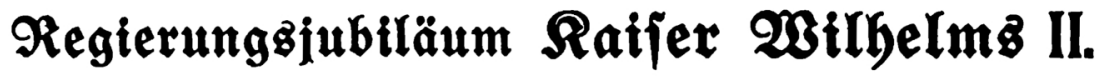

und zur

פabrhunbertfeier ber Befretungżriege

\author{
unter Förberung Der Genate
}

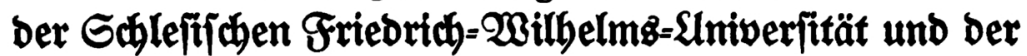

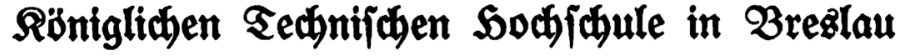

berausigegeben bon

Dr. Grif Gred) und Dr. Franz Ramperş,

Profefforen an ber Univerfität Breslau

In zroei abteilungen:

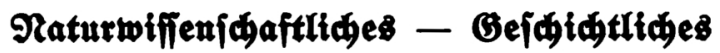

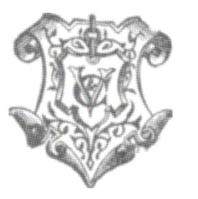

Reipzig

Berla'g von Beit \& Comp. 



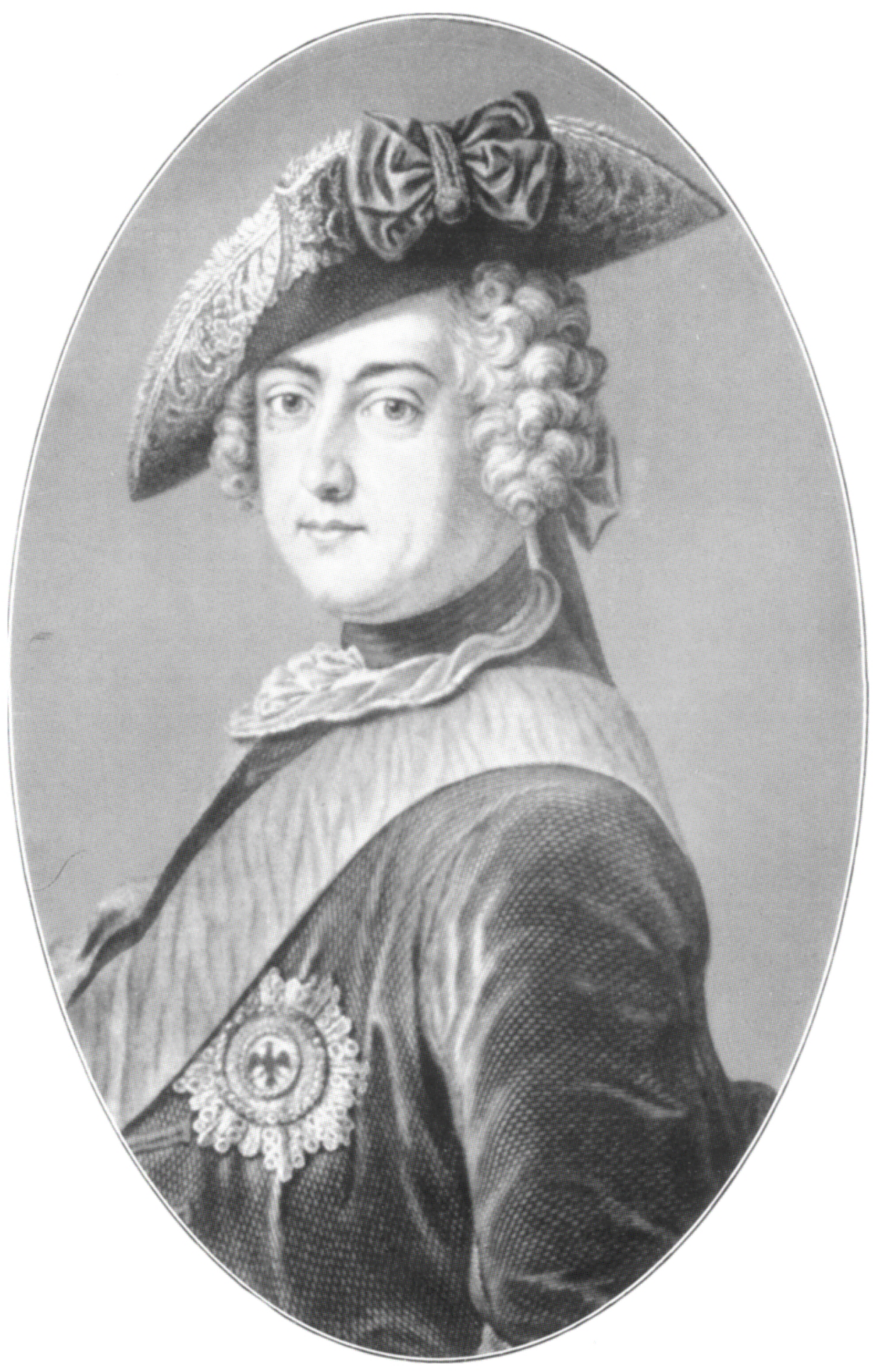

Friebrich) Der (Bropje. 





\section{Shle eijiche Sandeskunde $=$}

\section{(Beidituthtide abteifung}

\section{Unter Mitwirtung von}

Geh. Ronifítorial= Rat Prof. Dr. Utmolb, Dozent Dr. $\mathfrak{B r a n n}$, Probinztal = Ronjervator Regierung $8=$ und Baurat Dr. Burge= meifter, Genatzpräjibent Prof. Dr. Engelmann $t$, Dozent a. b. Tectin. Sochidulue Dr. Fif Obertanomeffer Sellmidh, Geh. Reg.= Rat Wrof. Dr. Raufmann, Prof. Dr. Rinfeldey, Geh. Reg. $=$ Rat $\mathfrak{P r o f}$. Dr. Rod, Privatboz.

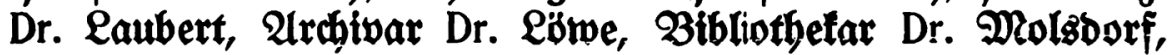
Prof. Dr. Rublowght, Prof. Dr. Geger, Priwatboz. Dr. Geppelt, Prof. Dr. Giebz, Lanbrat v. 3ajtrow, Prof. Dr. 3iefurid

Gerausgegeben von

\section{Dr. Granz $\mathfrak{R a m p e r z}$}

Profeffor an ber siniverfităt Brestau

Mit einem Titelbiltb, 21 abbitbungen in Tertt, 73 Tafeln und einem Gatimile.

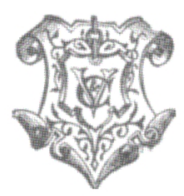

Qeipzig

Berlag von Beit \& Comp. 
Drud von Megger \& $234 t t g$ in Relpals 
Geiner Majeftät

bem Deutichen Raijer unb Rönig von Preuß̄en

\section{Wiilkelm II.}

unferm Serzog von Gallefien zur

25. Wiebertebr ber $\mathfrak{S b r o n b e f t e i g u n g ~}$

ebrfurchtzovd zugeetgnet

von ben Serausgebern 
